\title{
Modes of genetic transmission of dyslexia in South Indian families
}

\author{
P. Saviour, N. B. Ramachandra \\ Human genetics Laboratory, Department of Studies in Zoology, University of Mysore, Manasagangothri, Mysore-570006, India
}

BACKGROUND: Dyslexia is a major educational problem, but the studies on genetics of dyslexia are very limited in India. There is a great dearth of proper statistical data to show the incidence of dyslexia in Indian population. More over inheritance pattern of dyslexia is not well established in our population.

AIMS \& OBJECTIVE: To establish the inheritance pattern of dyslexia in 23 selected families.

MATERIALS AND METHODS: We have ascertained 23 dyslexic probands and their families from the state of Karnataka. Individuals with above 8 years of age, normal performance intelligence quotient $(>85)$ and remarkable deviation in reading and writing skills compared to chronological age were considered for the study. Based on the genetic registry pedigrees of the families were constructed. RESULTS: Based on the affectedness, the dyslexia phenotypes were classified into four types: severe reading spelling deficit, mild reading spelling deficit, severe spelling deficit and mild spelling deficit. Severe dyslexia phenotypes were more frequent than mild phenotypes. Mild spelling deficits were better compensated than the other types. It was found that autosomal dominant inheritance pattern of dyslexia was more prevalent than autosomal recessive and sporadic pattern in the present study.

CONCLUSION: Family history of dyslexia is a consistent risk factor; therefore this knowledge can be applied to the prevention and remediation of dyslexia.

Key words: Dyslexia, Reading-spelling deficit, Spelling deficit, Phenotype, Inheritance

Acquisition of language has become ever more important in this information age. Most children acquire it naturally in a sequence of listening, speaking, reading and writing. ${ }^{[1]}$ Failure in any of these processes may lead to life long socioeconomic and mental health consequences. ${ }^{[2]}$ There are many causes of language disability; the most common is developmental dyslexia, which is defined as difficulty in learning to read and spell despite adequate education, intelligence, sociocultural opportunities and without any obvious sensory deficits. ${ }^{[3]}$
It accounts for $80 \%$ of learning disabilities. The phenotype of dyslexia is complex and different phenotype dimensions can be distinguished. ${ }^{[4]}$ Although multiple etiologies are proposed for the this complex trait exact cause still remains unknown but substantial evidence from genetic and neurobiological studies suggest that dyslexia is a disorder which is influenced by genetic factors and the underlying deficit is in the language areas of the brain.

Though dyslexia is a major educational problem, no much study has been done on the family patterns of dyslexia in India. There is a great dearth of proper statistical data to show the incidence of dyslexia in Indian population. Here we report the patterns of genetic transmission of dyslexia in 23 Indian families.

\section{Materials and Methods}

We have selected 23 certified dyslexic probands and their families, diagnosed by clinical experts through psychometric tests, from the state of Karnataka. The inclusion criteria for the dyslexic subjects were, individuals above 8 years of age, normal performance intelligence quotient (>85) and remarkable deviation in reading and writing skills compared to chronological age. In addition, subjects with history of neurological disorders, mental retardation, psychological problems and major sensory handicaps were excluded from the study. To rule out the possible environmental factors such as children from low economic status and who have poor schooling were avoided. Information pertaining to age, religion, health status, medical, educational and family history of all the family members were recorded in the 
genetic registry. Based on the above informations pedigrees were constructed. Informed consent was obtained from the subjects and parents before inclusion in the study.

\section{Results}

Out of 23 families, 19 were extended families and four were nuclear families. All the families were Dravidians and their native language was Kannada. Table 1 provides comprehensive data on the frequency of individuals affected with different dyslexia phenotypes and compensation rate of those deficits. Out of 392 individuals of 23 families screened; about $53 \%$ and $47 \%$ were males and females respectively. Of the 109 individuals affected, $62.39 \%$ and $38.53 \%$ were males and females respectively [Table 1]. $\chi^{2}$ test reveals that there is significant difference between affected males and females. Affected individuals in the families ranged from 1 to 26 . Based on the affectedness of the trait, these individuals were classified into severe dyslexics and mild dyslexics. Both severe and mild dyslexics were shown two phenotypes, reading-spelling deficit as well as only spelling deficit. Figure 1 illustrates high frequency of severe reading-spelling deficit. Individuals who have severe spelling deficit was better compensated the difficulty than severe reading-spelling deficit [Figure 2]. Mild spelling deficit was better compensated than that of other deficits.

Three generation pedigrees of 23 families revealed three types of inheritance patterns of dyslexia, viz, autosomal dominant inheritance, autosomal recessive inheritance and sporadic cases [Table 2]. Of these, autosomal dominant inheritance was more prevalent

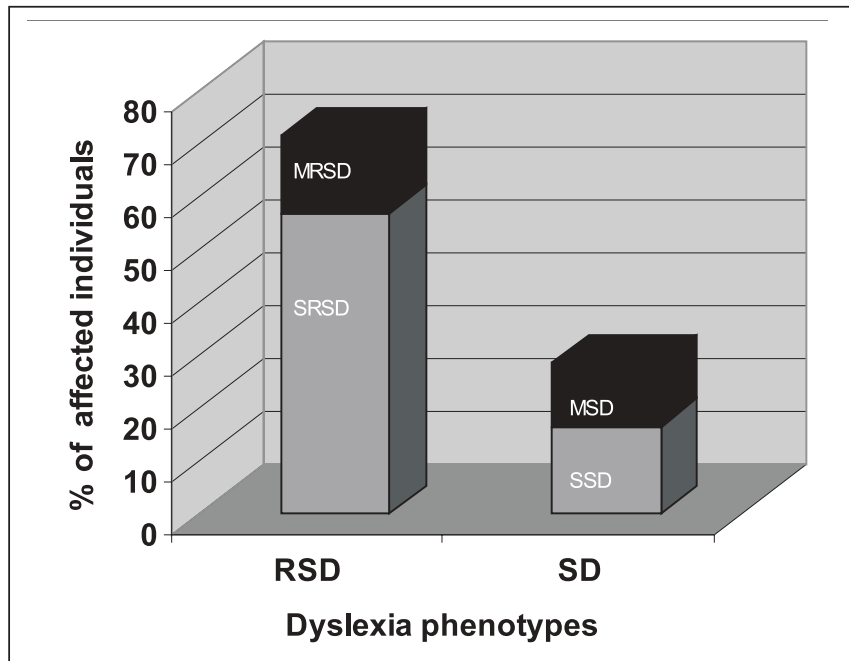

Figure 1: Percentage of individuals affected with different dyslexia phenotypes

RSD = reading-spelling deficit, $S D=$ spelling deficit, SRSD=severe reading-spelling deficit, $M R S D=$ mild reading-spelling deficit, $S S D=$ severe spelling deficit MSD=mild spelling deficit

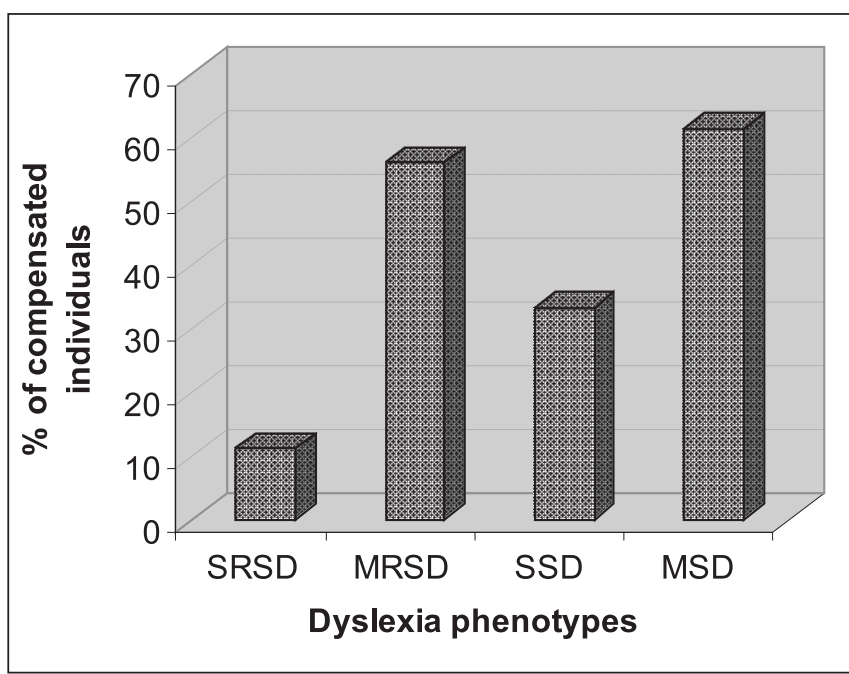

Figure 2: Percentage of individuals who compensated different dyslexia

phenotypes. SRSD=severe reading-spelling deficit, $M R S=$ mild reading-spelling deficit, $S S D=$ severe spelling deficit, MSD=mild spelling deficit

Table 1: Frequency of different dyslexia phenotypes in 23 dyslexic families

\begin{tabular}{|c|c|c|c|c|c|c|c|c|c|}
\hline & & \multicolumn{2}{|c|}{ Total } & \multicolumn{2}{|c|}{ Male } & \multicolumn{2}{|c|}{ Female } & \multicolumn{2}{|c|}{ Compensation of the defects } \\
\hline & & \# & $\%$ & \# & $\%$ & \# & $\%$ & Male in \% & Female in \% \\
\hline Families Screened & & 23 & - & - & & - & & - & - \\
\hline Individuals screened & & 392 & - & 208 & 53.06 & 184 & 46.94 & - & - \\
\hline Individuals affected & & 109 & 27.81 & $68^{*}$ & 62.39 & $41^{*}$ & 38.53 & 46.02 & 5.50 \\
\hline Reading,spelling & SevereDeficit & 62 & 56.88 & 23 & 37.10 & 32 & 51.61 & 6.45 & 4.84 \\
\hline deficit $(78)^{\star *}$ & Mild Deficit & 16 & 14.68 & 9 & 12.5 & 3 & 31.25 & 50.00 & 6.25 \\
\hline \multirow[t]{2}{*}{ Spelling deficit $(31)^{* *}$} & SevereDeficit & 18 & 16.51 & 2 & 50.00 & 5 & 16.67 & 27.78 & 5.55 \\
\hline & Mild Deficit & 13 & 11.93 & 4 & 30.77 & 1 & 7.69 & 53.85 & 7.69 \\
\hline
\end{tabular}

${ }^{*} \chi^{2}=6.2 ; \mathrm{df}=1 ; \mathrm{p}<0.05 ;{ }^{*} \chi^{2}=19.42 ; \mathrm{df}=1 ; \mathrm{p}<0.01$ 
Table 2: Frequency of families showing different inheritance pattern of dyslexia

\begin{tabular}{|c|c|c|c|c|c|c|}
\hline \multirow[t]{3}{*}{ Type of inheritance } & \multirow{2}{*}{\multicolumn{2}{|c|}{ No of Families (Total no=23) }} & \multirow{2}{*}{\multicolumn{2}{|c|}{$\begin{array}{l}\text { Frequency of families showing } \\
\text { Reading and Spelling deficit in }\end{array}$}} & \multirow{2}{*}{\multicolumn{2}{|c|}{ Spelling deficit in }} \\
\hline & & & & & & \\
\hline & $\#$ & $\%$ & $\#$ & $\%$ & $\#$ & $\%$ \\
\hline Autosomal Dominant & $15^{*}$ & 65.22 & 14 & 60.87 & 1 & 4.35 \\
\hline Autosomal Recessive & $4^{*}$ & 17.39 & 4 & 17.39 & - & - \\
\hline Sporadic & $4^{*}$ & 17.39 & 1 & 4.35 & 4 & 13.04 \\
\hline
\end{tabular}

${ }^{*} \chi^{2}=10.53$ at df $2, P$ value $>0.01$

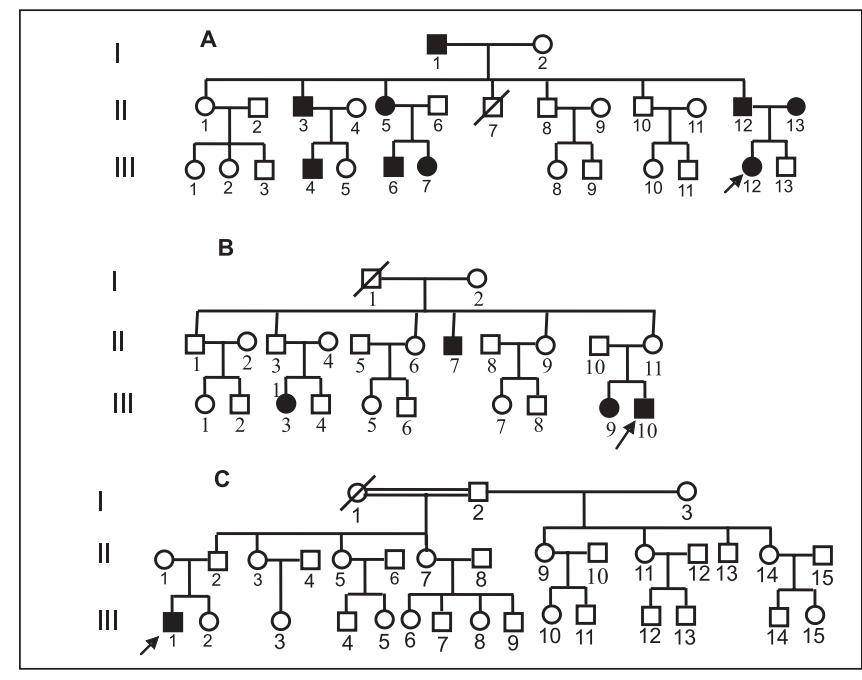

Figure 3: Pedigree belonging to category ' $A$ ' represents autosomal dominant inheritance pattern of the trait, ' $B$ ' represents recessive inheritance and ' $C$ ' represents sporadic case of dyslexia. Squares indicate males and circles indicate females, the filled symbols indicate dyslexic individuals. The arrow directed to the filled symbol represents the proband. The Roman number in the left side of the figure indicates the number of generations. The Arabic number below the symbol denotes the number of individuals in that generation

(65.22\%) than other types. Reading-spelling deficit had shown all the three types of inheritance patterns however, autosomal dominant pattern was seen in most of the cases. Spelling deficit had shown more of sporadic pattern than autosomal dominant inheritance pattern, while autosomal recessive inheritance of spelling deficit was not found in any of the pedigrees. Pedigrees are presented in Figure 3 showing each category of inheritance pattern. Out of 23 families, 8 families showed consanguineous marriage where three families showed sporadic pattern of spelling deficit, three families were consistent with autosomal dominant pattern of readingspelling deficit and two families had shown autosomal dominant inheritance of both reading-spelling deficit and spelling deficit.

Out of 109 dyslexics, it was found that 21 Dyslexic individuals were allergic to dust, milk products and to certain vegetables like radish and citrus fruits. It was also found 9 dyslexic individuals were left handed and 33 individuals had short sight which is corrected using appropriate lens. Eighteen subjects had speech delay in the early childhood.

\section{Discussion}

The prevalence of dyslexia ranges from $3-17.5 \%$ of the school age children. ${ }^{[5-7]}$ To our knowledge such prevalence studies has not been done in India. In the present study, among the selected families, the prevalence of dyslexia is found to be $27.8 \%$. This indicates that occurrence of dyslexia is much more $(\sim 1 / 3)$ among the individuals of the family. As in other studies ${ }^{[8-9]}$ males are more affected than females $(1.6: 1)$. It is found that reading-spelling deficit is the common phenotype of dyslexia. It is interesting to note that reading difficulty is always associated with spelling deficit and not vice versa. Compensation rate is more among individuals affected with mild reading-spelling deficit and it is least in severe reading-spelling deficit. Individuals who have severe spelling deficit are better compensated than those with severe reading-spelling deficit. Number of individuals compensated mild spelling deficit out numbers rest of the individuals with other deficits. This suggests that individuals with mild dyslexia phenotypes ( $>50 \%$ ) show higher compensation rate than that of individuals with severe dyslexia phenotypes. Compensation of the deficits to a maximum extent is possible by providing special education; otherwise the deficit will remain as such.

In this era of genomics, families are still the starting point of genetic investigations. Familial aggregation of dyslexia was first reported in the turn of the last century. ${ }^{[10]}$ Many studies have been done on familiality, heritability and modes of transmission of dyslexia which sug- 
gest genetic factors have significant role in predisposition of dyslexia. ${ }^{[11-13]}$ Different genetic models of dyslexia have been postulated and there is evidence for both polygenic and monogenic inheritance. ${ }^{\left[{ }^{14]}\right.}$ Hallgren $^{[15]}$ was noted autosomal dominant transmission of dyslexia in $80 \%$ of the families studied. Pennington et $a^{\left[{ }^{[16]}\right.}$ also found that in $20-30 \%$ of families with dyslexic children, the inheritance pattern is autosomal dominant. Contrary to this, Lewitter et $a{ }^{\left[{ }^{[17]}\right.}$ and Grigorenko et al ${ }^{[18]}$ reported that there was no evidence for a single major locus, autosomal dominant, autosomal recessive or codominant transmission. On the other hand, inheritance of dyslexia in Indian families is poorly understood. In the present study, autosomal dominant, autosomal recessive and sporadic patterns of dyslexia are recorded, of which, autosomal dominant pattern is seen in majority of the cases. Autosomal dominant inheritance is more frequent in the dyslexic families as it is not fatal for the individual.

With the advancement of human genome research geneticists have made substantial progress in identifying the genetic basis and also there have been numerous reports of loci, DYX1 at 15q21, DYX2 at 6p21.3, DYX3 at 2p16-p15, DYX5 at 3p12-q13, and DYX6 at $18 p 11.2$ which are involved in genetic predisposition of dyslexia. ${ }^{[4,19-22]}$ These genetic loci may harbor many genes which are responsible for this complex trait. Each phenotype of this complex trait may be controlled by a gene(s). Therefore, isolation of the defective genes will initiate a new phase of research which will provide a more fundamental understanding of the nature of dyslexia, eventually leading to early diagnosis, risk estimation, better methods of treatment and prevention.

Dyslexia is found to be associated with retarded speech development, ${ }^{[4,23]}$ left handedness and autoimmune disorders. ${ }^{[17]}$ Present study also recorded a few cases of speech delay in the early childhood, left handedness and auto immune diseases associated with dyslexia. It is well known that consanguineous marriages increase the inheritance of defective genes in the family. In the present study about $30 \%$ of the families are with consanguineous marriages which could be a factor for the high prevalence of dyslexia in these families.

A family history of dyslexia is a consistent risk factor and this knowledge can be applied to the prevention and remediation of dyslexia. Without specialized knowledge of familial dyslexia patterns it is often difficult to exclude familial clustering and respond adequately to the concerns of the affected individuals. The pupils with dyslexia are generally ignored and promoted to higher grades until they become dropouts or delinquents. High prevalence of dyslexia could be one of the factors for the high illiterate population in India. Once children are diagnosed as dyslexic, they would require specific intervention and ongoing support if they are not to be further handicapped in their learning. Therefore, more studies on dyslexia are required in India and we feel that there should be implementation of legislation in the country to take utmost care of these children because dyslexia is an invisible handicap.

\section{Acknowledgements}

Financial support from the Central Institute of Indian Languages, Mysore, to initiate genetic study is gratefully acknowledged. We thank the chairman, DOS in Zoology, University of Mysore for providing facility to conduct this work, Prof. H. A. Ranganath for the encouragement and Smitha $\mathrm{R}$ for the help during the study. PS is grateful to University of Mysore for awarding UPGJRF fellowship.

\section{References}

1. Gayan J, Smith SD, Cherny SS, Cardon LR, Fulker DW, Brower AM, et al. Quantitative trait locus for specific language and reading deficits on chromosome $6 \mathrm{p}$. Am J Hum Genet 1999;64:157-64.

2. Shaywitz SE. Dyslexia. N Engl J Med 1998;338:307-12.

3. Chase CH, Rosen GD, Sherman GF. Developmental Dyslexia:neural, cognitive and genetic mechanisms. Baltimore, York press. 1996.

4. Schulte-Körne G, Nöthen MM, Muller-Myhsok B, Cichon $S$, Vogt IR, Propping P, et al. Evidence for linkage of spelling disability to chromosome 15 . Am J Hum Genet 1998;63:279-82.

5. DeFries JC, Fulker DW, LaBuda MC. Evidence for a genetic aetiology in reading disability of twins. Nature 1987;329:537-9.

6. Lerner JW. Educational interventions in learning disabilities. J Am Acad Child Adolesc Psychiatry 1989;28:32631.

7. Shaywitz SE, Shaywitz BA, Pugh KR, Fulbright RK, Constable Rt, Mencl WE, et al. Functional disruption in the organization of the brain for reading in Dyslexia. Proc Natl Acad Sci 1998;95:2636-41. 
8. Smith SD, Kimberling WJ, Pennington BF, Lubs HA. Specific reading disability:identification of an inherited form through linkage analysis. Science 1983;219:13458.

9. Shaywitz SE, Shaywitz BA, Fletcher JM, Escobar MD. Prevalence of reading disability in boys and girls. JAMA 1990;264:998-1002.

10. Thomas CJ. Congenital "word blindness" and its treatment. Ophthalmoscope 1905;3:380-5.

11. Stevenson J, Graham P, Fredman G, McLoughlin V. A twin study of genetic influences on reading and spelling ability and disability. J Child Psychol Psychiatry 1987;28:229-47.

12. Stevenson J. Which aspects of processing text mediate genetic effects? Reading and Writing:An Interdisciplinary Journal 1991;3:249-69.

13. DeFries JC, Alarcon M. Genetics of specific reading disability. Ment Retard Dev Disabil Res Rev 1996;2:39- 47.

14. Wolff PH, Melngailis I. Family patterns of developmental Dyslexia:clinical findings. Am J Med Genet 1994;54:12231.

15. Hallgren B. Specific dyslexia ('congenital word blindness'): A clinical and genetic study. Acta Psychiatr Neurol Scand 1950;65:1-27.

16. Pennington BF, GilgerJ, Pauls D, Smith SS, Smith SD, DeFries JC, et al. Evidence for a major gene transmis- sion of developmental dyslexia. Journal of the American Medical Association 1991;18:1527-34.

17. Lewitter FI, DeFries JC, Elton RC. Genetic model of reading disability. Behaviour Genetics 1980;10:9-30.

18. Grigorenko EL, Wood FB, Meyer MS, Hart LA, Speed WC, Shuster A, et al. Susceptibility loci for distinct components of developmental Dyslexia on chromosome 6 and 15. Am J Hum Genet 1997;60:27-39.

19. Cardon LR, Smith SD, Fulker DW, Kimberling WJ, Pennington BF, DeFries JC. Quantitative trait locus for reading disability on Chromosome 6. Science 1994;266:276-9.

20. Fagerheim T, Raeymaekers $P$, Tonnessen FE, Pedersen M, Tranebjaerg L, Lubs HA. A new gene (DYX3) for Dyslexia is located on chromosome2. J Med Genet 1999;36:664-9.

21. Nopola-Hemmi J, Myllyluoma B, Haltia T, Taipale M, Ollikainen V, Ahonen T, et al. A dominant gene for developmental dyslexia on chromosome 3. J Med Genet 2001;38:658-64.

22. Fisher SE, DeFries JC. Developmental Dyslexia:Genetic Dissection of a complex cognitive trait. Nature reviews/ Neuroscience 2002;3:767-80.

23. Smith SD, Kimberling WJ, Pennington BF. Screening of multiple genes influencing dyslexia. Reading and writing:An interdisciplinary journal 1991;3:285-98.

\section{Subscription rates}

Indian Journal of Human Genetics

Publication of The Indian Society of Human Genetics
ISSN: 0971-6866

Published by:

Medknow Publications www.medknow.com

\section{Subscription Rates for 2006}

\begin{tabular}{|l|r|c|}
\hline & Annual & Individual issues* \\
\hline In India (Rs.) & 1500.00 & 400.00 \\
Abroad (US \$) & 150.00 & 40.00 \\
\hline
\end{tabular}

${ }^{*}$ Please include Rs.50/\$5 for postage and handling

- Published three time in a year, subscriptions are for calendar year only

- Please return this coupon to:

Medknow Publications

A-109, Kanara Business Centre, Ghatkopar (E), Mumbai - 400075, India

- Cheque should favour "Medknow Publications"

- Please allow at least six to eight weeks for commencement of new subscription.

- Claims for missing issues can be made only within one month of publication 